\title{
¿ES LA DEMOCRACIA MODERNA RESULTADO DE LAS TEORÍAS POLÍTICAS OCCIDENTALES? \\ El caso de la liga iroquesa y la constitución estadounidense \\ María Julia Sierra*
}

RESUMEN: Este texto destaca la influencia y participación de la Liga iroquesa -conjunto de grupos amerindios- en la unificación de las colonias inglesas de América y en la creación del sistema federalista de Estados Unidos. Mediante la labor de algunos intelectuales como Franklin y Morgan, la influencia iroquesa se puede constatar en Marx y Engels y en el siglo XX con los movimientos de reivindicación cultural.

Palabras Clave: Liga iroquesa, Costitución estadounidense, Benjamín Franklin, Lewis Morgan, democracia.

\section{IS OUR MODERN DEMOCRACY A PRODUCT OF WESTERN POLITICAL THEORY? \\ THE CASE OF THE IROQUOIS NATION AND THE AMERICAN CONSTITUTION}

ABSTRACT: In this article, we will highlight the influence and the role of the Iroquois nation -a group of North American Indians- in the unification of the English colonies of America and in the creation of the American federal system. Due to the work of intellectuals like Franklin and Morgan, the Iroquois influence can be seen in Marx and Engels and in the twentieth century movements of cultural revindication.

KEYWORDS: Iroquois Nation, American Constitution, Benjamin Franklin, Lewis Morgan, democracy.

* Departamento Académico de Estudios Generales, ITAM. 


\section{¿ES LA DEMOCRACIA MODERNA RESULTADO DE LAS TEORÍAS POLÍTICAS OCCIDENTALES? \\ El caso de la liga iroquesa y la constitución estadounidense}

\section{Introducción}

\section{Las relaciones interculturales desde el siglo $X V I$}

Todos hemos oído hablar de los intercambios entre los europeos y los pueblos indígenas de América. Siempre se enumeran plantas, animales, metales y productos que pasaron de uno a otro continente; ${ }^{1}$ con todo esto se transformó la economía del sistema

${ }^{1}$ Como ejemplos de productos americanos que llegaron a Europa se pueden citar: metales y piedras preciosas como la plata y las esmeraldas; jitomate, aguacate, cacao, chocolate, guajolotes o pavos, grana, cochinilla, papa, y muchos otros. Entre los productos que los europeos trajeron al nuevo continente podemos mencionar: ovejas, vacas, cabras, caballos, trigo, cebada, centeno, vid, aceitunas, algodón, paños de lana, así como diversas tecnologías agrícolas, mineras y textiles. mundial. Se cambiaron los hábitos alimenticios y de consumo; los paisajes se transformaron con los nuevos cultivos y las nuevas actividades económicas, en uno y otro lado del Atlántico. No todos los intercambios fueron positivos: los españoles también trajeron al nuevo continente muchos gérmenes que diezmaron a las poblaciones aborígenes, ${ }^{2}$ porque éstas no tenían los anticuerpos requeridos para sobrevivir, lo que facilitó las conquistas militares y los procesos de colonización. Las corrientes

${ }^{2}$ Cfr. Sherburne F. Cook y Woodrow Borah, Ensayos sobre historia de la población: México y el Caribe, 1968, México, Siglo XXI, traducción de Clementina Zamora. En esta investigación se habla de un verdadero desastre demográfico, pues la población mesoamericana sufrió un descenso de casi las tres cuartas partes del total en sólo una generación. 
migratorias se ampliaron y modificaron, produciendo nuevos patrones de poblamiento y diversas formas de mestizaje, que cambiaron la distribución de la población alrededor del mundo.

Se sabe que el proceso de "conquista cultural" no fue sencillo, que hubo resistencias y enfrentamientos violentos. Se crearon nuevas realidades sincréticas que tienen expresiones muy claras en el arte, que tuvo uno de sus clímax en la cultura barroca de América Latina (siglos XVII y XVIII). El discurso de La Angostura, pronunciado el 15 de febrero de 1819 por Simón Bolívar, muestra claramente la conciencia de esta nueva identidad, producto de lo que llamaríamos "mestizaje cultural", cuando afirmó: "No somos europeos, no somos indios, sino una especie media entre los aborígenes y los españoles [...]. Tengamos presente que por nuestras instituciones y por nuestro carácter no somos una emanación de Europa". ${ }^{3}$

Se reconoce que los occidentales trajeron nuevas tecnologías agrícolas, arquitectónicas y militares, así como muchas instituciones; asimismo impusieron sus lenguas y visiones del mundo. Sin embargo, tal pareciera que nunca se consideró la

${ }^{3}$ http://www.columbia.edu/cu/spanish/courses/spanish3350/02independencia/pdf/angostura.pdf, consultada el 12 marzo 2014. influencia de las ideas o sistemas políticos y sociales de los indios en las instituciones de Occidente hasta finales del siglo XX. Paradójicamente, aunque algunos ilustrados consideraron a los indios de América como salvajes, también elogiaron algunas de sus instituciones y costumbres, al punto de inspirarse en ellas, tal como se verá más adelante.

\section{La cuestión antropológica}

Los descubrimientos y conquistas de los siglos XV y XVI revolucionaron las formas de vivir, producir, organizarse, pensar y sentir. Desde el punto de vista antropológico, el aspecto más significativo fue la comprensión de la diversidad humana y la naturaleza de los "indios" que el descubrimiento de América hizo patente. La pregunta no sólo era teórica; se trataba de establecer las leyes que regularan los derechos y obligaciones de cada uno de los grupos socioculturales involucrados en la construcción del nuevo mundo. ${ }^{4}$

${ }^{4}$ Independientemente de algunas posturas que llegaron a considerar que los indios eran casi bestias o esclavos, la mayoría de las autoridades religiosas y el mismo emperador Carlos V los entendieron tan humanos que podían ser evangelizados. Además, como dice Paulo III, en la Bula Sublimis Deus: "A pesar de todo lo que pudo haber sido, o que se pudo decir en contrario, los 'indios' dichos, y 'todas las demás personas' que más tarde pueden ser descubiertas. de ninguna manera deben ser privadas de su libertad o despojadas de bienes, estén 
La constatación de la gran diversidad humana llegó al centro de la reflexión de la Antropología como ciencia, es decir, de las relaciones entre "nosotros" (los que pertenecen a mi cultura y sociedad) y los "otros" (los extraños que no son parte de mi grupo). Sin embargo, mi identidad personal se construye con referencia a ellos. Esto es lo que algunos filósofos como Paul Ricoeur ${ }^{5}$ llaman "el problema de la otredad y la mismidad" y, en última instancia el de la unidad humana. El debate ha continuado a lo largo de los años y ha revestido características diferentes, según los lugares y los valores de los participantes. Los protagonistas principales fueron occidentales hasta la segunda mitad del siglo XX, en que también algunos de los "otros" exigieron ser oídos.

dentro o fuera de nuestra fe, y que pueden y deben, libremente y legítimamente, disfrutar de la libertad y la posesión de sus bienes; tampoco deben ser de ninguna manera esclavizadas, y si ocurre en contrario, entonces eso será nulo y no tendrá efecto". Véase, entre muchos otros: a) Leyes de Burgos, 1512; b) Los Justos Títulos, de fray Francisco de Vitoria en De indis, 1532; c) Bula Sublimis Deus, Paulo III, 1537; d) Junta de Valladolid y la Polémica entre fray Bartolomé de las Casas y Ginés de Sepúlveda, 1550-1551.

${ }^{5} \mathrm{Cfr}$. Paul Ricoeur, El sí mismo como otro, 1995, México, siglo XXI, .

\section{El debate ilustrado}

\section{Natura y cultura}

La reflexión sobre la posibilidad de la unidad humana a pesar de las diferencias llegó al ámbito de la biología. Hubo quienes sostuvieron que había grados de humanidad, de manera que los indios eran inferiores biológicamente; así, se desarrollaron muchas de las corrientes racistas que sobreviven hasta nuestros días. Otras escuelas afirmaban que las causas de la diversidad estaban en el medio ambiente que determinaba el comportamiento humano. Algunos, en cambio, negaron las tesis racistas o deterministas y plantearon la importancia de la cultura en la historia humana.

Los ilustrados franceses como Voltaire y Rosseau, en la primera mitad del siglo XVIII, sostuvieron que el descubrimiento de América fue uno de los grandes acontecimientos de la historia, porque este hecho señala el momento en que la mitad de la humanidad se encontró con la otra, a la que ignoraba. ${ }^{6}$ Así, desde los inicios de la Ilustración, la percepción que tuvieron estos pensado-

${ }^{6}$ "C' $\mathrm{C}$ 'est ici le plus grand événement sans doute de notre globe, dont une moitié avait toujours été ignorée de l'autre. Tout ce qui a paru grand jusqu'ici semble disparaître devant cette espèce de création nouvelle", Voltaire, Essai sur les moeurs, 1972, Paris, PUF, p. 387. 
res frente a la diversidad humana se caracterizó por sus matices igualitarios. En 1875, Jean Jacques Rousseau, en su Discurso sobre el origen de la desigualdad entre los hombres 7 afirmó que la humanidad en sus orígenes era fundamentalmente buena; veía al salvaje en su estado primigenio como incorrupto, lleno de bondad y felicidad porque no había sufrido todavía las terribles desigualdades que existían en la sociedad civilizada.

Posteriormente las cosas cambiaron, porque medio siglo más tarde se llevó a cabo un debate importante que involucró a tres famosos ilustrados. Francisco Xavier Clavijero, uno de los jesuitas criollos novohispanos expulsados de su patria por el decreto de Carlos III de1767, publicó en Bolonia, en italiano, su obra más famosa, Historia antigua de México (1780): ${ }^{8}$ fue traducida a todos los idiomas europeos $\mathrm{y}$, al año siguiente, la completó con nueve disertaciones. El propósito de ambos escritos, tal y como lo afirmó en sus prólogos, fue "restituir a su auténtico esplendor la verdad sobre el México Antiguo,

${ }^{7}$ Cfr., Juan Jacobo Rosseau, Discurso sobre el origen de la desigualdad entre los hombres, http://moreliain.com/secciones/CULTYTRAD/ libros/Juan\%20J.\%20Rousseau\%20-\%20Discurso $\% 20$ sobre $\% 201 \mathrm{a} \% 20$ desigualdad.pdf, p. 48 , consultada el 2 de abril de 2014.

${ }^{8}$ Francisco Javier Clavijero, Historia Antigua de México, 1980, México, Porrúa, Sepan Cuántos, 29, prólogo Mariano Cuevas. verdad ofuscada por una turba increíble de escritores modernos". ${ }^{9}$ Entre los escritores a los que se dirigen sus refutaciones estaban: el naturalista francés Georges Louis Leclerc, conde de Buffon, quien fue uno de los precursores de la biología científica; el antropólogo holandés, Cornelius de Pauw; y el historiador escocés, William Robertson. Estos autores sostenían que los americanos antes de la Conquista eran salvajes, primitivos, incultos, faltos de intelecto, inferiores a los hombres del viejo continente. Los europeos que entraban en contacto con ese nuevo ambiente también se iban degenerando. ${ }^{10}$ Clavijero, como buen ilustrado, también buscaba "hacer prevalecer la razón por encima de los prejuicios" y más adelante critica:

Pauw escribe de los americanos desde su gabinete en Berlín, sin salir de él dice saber las cosas de América [...] No es la realidad occidental la que tienen estos ilustrados como norma suprema sino que es la razón de la superioridad europea la que sobrepasa todas las deter-

${ }^{9}$ Ibid., p. 9.

${ }^{10}$ Para lo cual daban como argumentos las descripciones de Fray Bartolomé de las Casas sobre la conquista de las Antillas. Cfr. la Brevísima relación de la destrucción de las Indias, http://aix1.uottawa. ca/ jmruano/relacion.pdf, consultada el 12 de marzo de 2014, Los escritos de Fray Bartolomé fueron utilizados como argumento en lo que después se llamó la "leyenda negra sobre los españoles". 
minaciones sociales e históricas en sus argumentos". ${ }^{11}$

En síntesis, las ideas que Clavijero sostiene a lo largo de toda su obra es que los indios de América tienen el mismo origen que los europeos, todos procedemos de Adán, por lo tanto los indios no son inferiores a los occidentales. Son igualmente racionales y la historia de las Indias tiene un pasado clásico, tan importante como los antecedentes grecolatinos de Europa. De manera que el mestizaje siempre proporcionará resultados positivos en la historia humana.

\section{Benjamín Franklin y los iroqueses}

Los iroqueses son un conjunto de grupos amerindios, habitaron alrededor de los Grandes Lagos, al sureste de Canadá, y al noreste de los Estados Unidos. ${ }^{12}$

A sí mismos se llamaban Nadowa o Haudenosaunee, es decir, "los de la casa extensa", donde cada uno tiene su propio fuego. Los franceses los llamaron iroqueses, del vocablo algon-

${ }^{11}$ Clavijero, op. cit, p. 25.

${ }^{12}$ Actualmente, en los Estados Unidos se encuentran grupos iroqueses en Nueva York, Wisconsin y Oklahoma; en la región de los lagos Ontario y Erie, Canadá, también existe una comunidad que migró a Francia en la época de la gran depresión, que vive en los departamentos de Aude y Garde de la región de Languedoc. Cfr. Charles Mann, 1491. Nueva historia de las Américas antes de Colón, 2006, México, Taurus. quino irinakhoiw (unión real). ${ }^{13} \mathrm{La}$ familia lingüística iroquesa cuenta con once idiomas. ${ }^{14}$ Eran pueblos nómadas que se volvieron sedentarios. Su economía era autosuficiente, el sistema era mixto basado en la agricultura (cultivaban diversas hortalizas), la silvicultura, la caza, la pesca y la recolección de ciertos frutos. Establecieron entre ellos el intercambio gratuito de regalos mutuos, ${ }^{15} \mathrm{y}$ comerciaban con otras tribus distintas a las de la Liga iroquesa (pieles y diversos abalorios). La propiedad de la tierra era comunal y el trabajo colectivo, con división social de acuerdo al sexo y a la edad. Cada tribu contaba con enormes extensiones de tierras.

Según la tradición oral haudenosaunee, ${ }^{16}$ alrededor del siglo XII ${ }^{17}$

${ }^{13}$ Los algonquinos son otro grupo de tribus amerindias que fueron aliados de los franceses en las guerras franco-británicas. Habitaron el extenso territorio entre Virginia y las Montañas Rocosas, al norte de la Bahía de Hudson. Actualmente, la mayoría de los algonquinos vive en Quebec, cfr., ibid.

${ }^{14}$ Las once lenguas son: tuscarora, nottoway, hurón, laurentiano, onondaga, conestoga, seneca, cayuga, mohawk, oneida y cherokee. Aunque no se ha podido probar el parentesco del iroqués con otras lenguas americanas, algunos lingüistas como Wallace Chafe dicen que podría estar relacionada con las lenguas siux.

${ }^{15}$ A este tipo de economía Marcel Mauss la llama "economía del don", cfr. M. Mausse, Essai sur le don, 1971, París, PUF.

${ }^{16}$ Según los estudios de Bárbara A. Mann y Jerry Fields de la Universidad de Toledo, en http:// iipdigital.usembassy.gov/st/spanish/publication/2009 /07/20090720115214pii0.9292108.html\#ixzz 2zgDS9A2h, consultada el 30 de marzo, 2014.

${ }^{17}$ De acuerdo con esta fecha, la Confederación iroquesa es el segundo modelo más antiguo de parlamento democrático y representativo. El Althing de 
surgió la confederación iroquesa, formada por el jefe hurón Deganawidah, "el Pacificador", quien consiguió la ayuda de Aiowantha (llamado Hiawatha algunas veces) para propagar su sueño de una confederación para controlar las rivalidades sangrientas entre las tribus. ${ }^{18}$ El esquema sociopolítico de la Confederación permitía combinar la soberanía de cada nación iroquesa con la de un gobierno confederado. Cada unidad soberana mantenía el poder sobre sus asuntos internos, mientras que el gobierno mancomunado regulaba y administraba lo relativo a las materias comunes a todos. El Consejo negociaba la paz, pero no podía declarar la guerra, la cual era decisión de los representantes o líderes de cada nación. ${ }^{19} \mathrm{El}$ jefe de la confederación, el Tododaho convocaba a los cincuenta sachems que representaban a los clanes de las cinco naciones; cada nación delegaba un número distinto de sachems, aunque estas diferencias no eran

Islandia fue el primero, porque se estableció en 930 a. C. Cfr. Jack Weatherford, Indian Givers: How the Indians of the Americas Transformed the World, New York, 1988, Fawcett Columbine, pp. 34-52.

${ }^{18} \mathrm{La}$ Confederación incluía originalmente a los mohawks, oneidas, onondagas, cayugas y senecas. La sexta nación, la de los tuscarora, migró al país iroqués a comienzos del siglo XVIII y fue adoptada por ellos. El sitio en el cual el pacto estableció como centro de la Liga se encuentra bajo la ciudad de Siracusa, Nueva York.

${ }^{19}$ Electos democráticamente. Cfr. Gregorio Doval, Breve historia de los indios norteamericanos, 2009, Madrid, Nowtilus. significativas porque todas las decisiones se tomaban por unanimidad, de acuerdo con la Gran Ley de Paz iroquesa. ${ }^{20}$

Benjamín Franklin, otro ilustrado americano, fue impresor, científico, inventor, político y el único padre fundador de Estados Unidos que firmó los cinco documentos que establecieron la Independencia de su país. ${ }^{21}$ Entre 1736 y 1762, en su imprenta de Filadelfia, publicó los tratados indios ${ }^{22}$ en pequeños folletos que tuvieron gran éxito en las colonias. $^{23}$

${ }^{20}$ Uno de los aspectos sobresalientes de esta ley es que, cuando el Consejo de sachems tenía que tomar una decisión realmente importante, sus miembros tenían que someter el asunto a la decisión de su pueblo, en una suerte de referendum, c $f r$. "The Constitution of the Iroquois Nations: The Great Binding Law", GAYANASHAGOWA, trad. Gerald Murphy, en http://www.indigenouspeople.net/ iroqcon.htm, consultada el 24 abril, 2014.

${ }^{21}$ Estos documentos son: 1) la Declaración de Independencia; 2) el Tratado de Concordia y Comercio con Francia; 3) el Tratado de la Alianza con Francia; 4) el Tratado de Paz con Gran Bretaña; y, 5) la Constitución de los Estados Unidos de América.

${ }^{22}$ Benjamín Franklin, Observaciones sobre los salvajes de Norteamérica, trad. del inglés María de los Ángeles Toda Iglesia, Sevilla, 2004, en http:// www.google.com.mx/url? sa $=\mathrm{t} \& \mathrm{rct}=\mathrm{j} \& \mathrm{q}=\&$ esrc $=\mathrm{s}$ \& source $=$ web\&cd $=2 \&$ ved $=\mathrm{C} 0 \mathrm{QFj} A B \&$ url $=\mathrm{http} \%$ $3 \mathrm{~A} \% 2 \mathrm{~F} \% 2 \mathrm{~F}$ revistas.uca.es\%2Findex.php $\% 2 \mathrm{Fcir}$ $\% 2$ Farticle $\% 2$ Fdownload $\% 2$ F286\%2F268\&ei=iy ZXU6TdJuTg2gWxqYD4DQ\&usg=AFQjCNHr6 j38J71 AyN6wp0ia5gojxprY3A, consultada el 20 de marzo de 2014.

${ }^{23}$ Cfr. Miguel León Portilla, De palabra y obra en el nuevo mundo: encuentros interétnicos, 1992, México, Siglo XXI. 
En la asamblea entre los indios y los británicos de Filadelfia, en 1744, el sachem iroqués Canassatego les dijo a los británicos que era necesario crear una organización que, sin afectar la soberanía de cada una de las trece colonias, permitiera unificar sus voces para tratar con otras naciones. ${ }^{24}$

En 1750, fue nombrado Comisionado de asuntos indios de Pennsylvania y, en 1754, participó en el Congreso de Albany, reunión organizada por la Cámara de Comercio Británica, que buscaba la alianza de los indios en contra de los franceses durante la Guerra de los Siete Años. ${ }^{25}$ En este Congreso, además de los delegados coloniales, asistieron los representantes de las seis naciones de la Confederación Iroquesa, bajo la dirección del sachem mohawk Hendrick Tejonihokarawa. Tanto Franklin como los iroqueses apoyaron el plan que buscaba unificar a las colonias inglesas, tomando como modelo a la Liga de los Iroqueses. ${ }^{26} \mathrm{El}$

${ }^{24}$ Las palabras que dirigió el sachem en esa asamblea fueron: "Nuestros antepasados sabios establecieron la Unión y la Amistad entre las Cinco Naciones. Esto nos hizo formidables; esto nos ha dado un gran peso y autoridad con nuestras naciones vecinas. Somos una confederación poderosa, y si ustedes observan los mismos métodos, los que han asumido nuestros antepasados sabios, ustedes adquirirán una fuerza y un poder semejantes. Por lo tanto, pase lo que pase, nunca se separen", http:/iipdigital. usembassy.gov/st/spanish/publication/2009/07/200 90720115214pii0.9292108.html\#ixzz2xKAhI200, consultada el 11 de abril de 2014.

${ }^{25}$ Los estadounidenses a esta guerra la llaman "las guerras indias".

${ }^{26} \mathrm{http}$ ://iipdigital.usembassy.gov/st/spanish/ publication/2009/07/20090720115214p ii0.9292108.html\#ixzz2zgDS9A2h, consultada el plan no se llevó a cabo por la oposición de los representantes del rey; sin embargo, el proyecto sirvió de ejemplo para algunas propuestas durante la Guerra de Independencia de los Estados Unidos. El Plan de Albany situó a Franklin como defensor de la confederación entre los creadores del sistema federalista de su país. En 1751 escribió al periodista y editor James Parker, quien trabajó con él:

Si seis naciones de salvajes fueron capaces de formar un esquema para unirse y llevar a la práctica su unión, de tal forma que ésta ha subsistido durante siglos como algo indisoluble, sería muy extraño que una unión de ese tipo no pueda ser llevada a cabo por diez o doce colonias inglesas. ${ }^{27}$

Esta carta sintetiza la dualidad que muchos ilustrados tuvieron frente a la realidad cultural de "los otros".

\section{EI siglo XIX y las reservaciones indias}

\section{Morgan y la antropología estadounidense}

Una vez concluida la Independencia estadounidense, el proceso de expan-

30 de marzo, 2014. Naturalmente, no sólo procede la estructura confederada del modelo de la Liga iroquesa, que aquí enfatizamos: hay que dar gran importancia también a la tradición política y social puritana, así como al utopismo revolucionario.

${ }^{27} \mathrm{Cfr}$. Bruce E. Johansen, Forgotten Founders, 1982, Harvard Common Press, en www.ratical.com/ many_worlds/6Nations/FF.html. Harvard Common Press en 1982, consultada el 3 de abril de 2014. 
sión territorial se aceleró y se convirtió en una parte sustantiva de la cultura norteamericana, cuya expresión más acabada fue la doctrina del Destino manifiesto, a fin de "extender el área de la libertad". Las alianzas con las tribus indias, que fueron decisivas en el triunfo de los británicos frente a los franceses, ya no eran necesarias. ${ }^{28}$ Las corrientes migratorias de Europa hacia el nuevo país se aceleraron. Los nuevos pobladores venían con sed de tierras para cultivar. Así,

${ }^{28} \mathrm{La}$ unidad política de la Liga Iroquesa empezó a desmoronarse desde la guerra de Independencia de Estados Unidos. Entre 1770-1785 los mohawk, senecas y cayugas apoyaron a los británicos mientras que los oneidas, onondagas y tuscaroras, a los rebeldes independentistas. Los que apoyaron a los ingleses lo hicieron pensando que se respetaría la proclama de 1763, que limitaba la expansión de los blancos sobre los territorios indios. La peste de viruela en 1776 diezmó a los onondagas, lo que aprovecharon los ingleses para celebrar un concejo en Oswego para conseguir la alianza con ellos, aunque los oneidas y senecas siguieron del lado de los estadounidenses. Entonces, John Sullivan dirigió una campaña contra las tribus iroquesas que apoyaban a la Corona británica y quemó 500 casas y muchas cosechas entre 1779 y 1780 . La firma del Tratado de París (1783) en la que los británicos reconocieron la independencia estadounidense no consideró a sus aliados indios a los que abandonó a su suerte. A pesar del apoyo de algunas naciones iroquesas y de numerosas tribus indias a los estadounidenses, ninguna pudo mantener sus territorios originales. El acuerdo de 1763 fue sustituido por la Paz de Fort Stanwix de 1784, que expandió las líneas fronterizas entre indios y blancos, obligando así a los indios a ceder sus tierras y a renunciar a toda reivindicación sobre Ohio, Pennsylvania y el oeste de Nueva York. Con la venta de las tierras indígenas los norteamericanos pagaron parte de su deuda externa. Cfr. John Reed Swanton, The Indian Tribes of North America, 2007, Baltimore, Genealogical Publishing Company, pp. 88-123. surgieron más conflictos con los únicos grupos originarios de Norteamérica, a causa de las violaciones a sus territorios, quienes terminaron por levantarse en armas. Finalmente los indios perdieron y los pocos que quedaron fueron reducidos a reservaciones; así fue como los blancos se apoderaron de más de las tres cuartas partes de los territorios indígenas. ${ }^{29}$

En medio del auge de las concepciones evolucionistas y en el contexto de las teorías dominantes como el darwinismo social ${ }^{30}$ y el spencerismo, ${ }^{31}$ la dualidad ilustrada desapareció y las actitudes racistas, fundamentadas en las ideas de la supervivencia del más apto y la superioridad de ciertos grupos, se incrementaron significativamente; sin embargo, hubo algunas voces disidentes que fundaron la Antropología científica, uno de ellos fue Morgan.

Lewis H. Morgan nació en Aurora, Nueva York y estudió en la Academia Coyunga, en territorio iroqués, donde se hizo amigo entrañable de Ely Parker, de la tribu seneca, quien

${ }^{29}$ Cfr. Howard Zinn, La otra historia de los Estados Unidos, 1999, México, Siglo XXI, pp. 99-114.

${ }^{30}$ La teoría de la evolución de las especies de Charles Darwin fue aplicada por pensadores como Herbert Spencer a todos los ámbitos sociales: económicos, políticos y culturales, distorsionado el sentido original de su autor.

${ }^{31}$ Spencer fue uno de los que iniciaron la sociología; además de evolucionista, también se le considera positivista y materialista. Sus seguidores tuvieron auténticas posiciones eugenésicas. 
lo introdujo en los serios problemas que estaban experimentando los aborígenes en la nueva nación; más tarde estudió derecho en el Union College. El primer caso que llevó, junto con Parker, fue la defensa de las tierras de los iroqueses en un pleito contra una compañía de bienes y raíces que quería arrebatarles una gran porción de su territorio mediante una estafa. Morgan llevó el caso hasta el Congreso, donde lograron ganar el pleito. En agradecimiento, las tribus lo adoptaron con el nombre de Ta-ya-da-o-whu-kuh (puente entre dos pueblos). En 1851 fundó, junto con unos amigos, un club social inspirado en la mitología griega, llamado $L a$ orden del nudo gordiano; posteriormente, la sociedad se transformó en otra, basada en las costumbres iroquesas, a la que bautizaron con el nombre de La gran orden o nueva confederación de los iroqueses. Entre los objetivos del club, además de estudiar a fondo la Liga Iroquesa que se había deshecho desde 1847 cuando los pueblos que la constituían fueron reducidos a reservaciones, estaban las de proporcionar apoyos económicos y legales a los indios seneca de la reserva Tonawanda, cerca de Rochester. En 1851 publicó su primera obra: $L a$ Liga de los Ho-dé-no-sau-nee (iroqueses). En su libro más importante, La sociedad primitiva, ${ }^{32}$ describió

${ }^{32}$ Lewis H. Morgan, La sociedad primitiva, 1972, Bogotá, Editorial Ayuso-Pluma. con todo detalle su teoría de la evolución de la sociedad: desde el salvajismo, pasando por la barbarie hasta llegar a la civilización, cualquier salvaje podía llegar a ser civilizado.

\section{Engels y Marx}

La obra de Morgan influyó profundamente en muchos pensadores decimonónicos, particularmente en Marx y Engels, quienes lo citan y sintetizan continuamente. Engels, en su libro El origen de la familia, la propiedad privada y el Estado, afirma:

Los iroqueses eran un pueblo valiente, vigoroso e inteligente, con un volumen cerebral próximo al promedio de los años. Elocuentes en la oratoria, vengativos en la guerra y de una perseverancia indómita, se han conquistado un sitio en la historia. Si sus proezas militares están empañadas por las atrocidades de la guerra salvaje, ellos han dado prueba de las más elevadas virtudes humanas en sus relaciones recíprocas. La confederación que organizaron debe ser mirada como un notable producto de la sabiduría y de la sagacidad. Uno de sus objetos declarados era el mantenimiento de la paz [...] Merced a su ubicación y poderío militar, ejercieron una notable influencia en el curso de los acontecimientos entre ingleses y franceses, 
en su rivalidad por la supremacía en norteamérica. Como en el primer siglo de la colonización los dos eran casi iguales en fuerzas y recursos, los franceses pueden culpar a los iroqueses en no pequeño grado del derrumbe de sus planes imperiales en el Nuevo Mundo. Para penetrar en el segundo plan de gobierno era necesario sustituir las gentes por municipios y distritos, reemplazar el régimen gentilicio por el territorial. El derrumbe de los gens y el surgimiento de municipios organizados señalan, en forma muy aproximada, la línea divisoria entre el mundo bárbaro y el civilizado, entre la sociedad antigua y la moderna. ${ }^{33}$

Marx decía que la organización política de los iroqueses era el equivalente americano de la democracia ateniense.

Durante el siglo XIX, el racismo entre las poblaciones de origen europeo se incrementó y se manifestó en muchas de las instituciones y costumbres de los blancos estadounidenses, que veían a los negros como esclavos y a los indios como enemigos salvajes a someter, olvidando lo mucho que dependían de ellos. Sólo aparecieron unas cuantas voces disidentes de los profesionales de la antropología.

${ }^{33}$ C. Marx y F. Engels, Obras escogidas, 1971, Moscú, Progreso, t. 3, "El origen de la familia, la propiedad privada y el Estado", pp. 203-352.

\section{Siglo XX y los movimientos de reivindicación cultural}

\section{Gandhi, Fanon y los procesos de descolonización}

En los inicios del siglo pasado una voz no occidental se alzó buscando la independencia de la India. El movimiento de Gandhi duró muchos años, en los que puso el ejemplo con sus ayunos, su pobreza y su paciencia; mostró la fuerza de la resistencia pacífica y defendió la grandeza cultural de su nación. Buscó que la India fuera ella misma y no a imagen y semejanza de Gran Bretaña.

Después de la Segunda guerra mundial y a raíz de los procesos de descolonización, se multiplicaron las voces de los "otros" que reclamaban su libertad y protestaban por el trato injusto que ejercieron sobre ellos los occidentales. Uno de los más famosos fue Frantz Fanon, un psiquiatra, filósofo y escritor, originario de Martinica. Nació en el seno de una familia con antepasados africanos, tamiles y blancos. Años más tarde apoyó al movimiento de independencia de Argelia y se unió al Frente de Liberación de Argel. Sus estudios sobre las psicopatologías de los colonizados son impresionantes; su obra tuvo gran influencia en los movimientos socioculturales y de reivindicación de los derechos civiles. 
Su libro más famoso, Los condenados de la tierra, ${ }^{34}$ fue prologado por Jean Paul Sartre; en él, el filósofo confesó que después de haber participado en la resistencia francesa para liberarse del dominio nazi le era inconcebible apoyar a Francia en su lucha para mantener sus dominios coloniales. Todo el tono del texto muestra una especie de vergüenza por lo que los occidentales hicieron con los colonizados. A diferencia de Gandhi, justifica la violencia de los movimientos libertarios, porque para él son el resultado de la violencia primera ejercida por los colonizadores.

\section{Martin Luther King y el movimiento por los derechos civiles}

Entre 1955 y 1968 muchas personas se unieron en contra de la segregación racial y para exigir la igualdad ante la ley y el acceso a todos los derechos civiles de cualquier ciudadano estadounidense, ya fueran blancos, negros o latinos. La lucha fue larga y dolorosa, con algunas explosiones de violencia; sus principales líderes fueron no violentos, como Martin Luther King, quien fue, al igual que Gandhi, brutalmente asesinado.

${ }^{34}$ F. Fanón, Los condenados de la tierra, 1963, México, FCE, prólogo de J.P. Sartre, trad. del francés Julieta Campos.

\section{Vine Deloria y el movimiento "Alcatraz red power"}

En los años setenta apareció, en Estados Unidos, un movimiento de defensa no sólo de los derechos civiles de los indios, sino también de reivindicación de sus derechos culturales. El autor, teólogo, historiador y activista Vine Victor Deloria, fue un indio siux que participó en el movimiento Poder rojo de Alcatraz, ${ }^{35}$ fue director ejecutivo del Congreso Nacional de los Indios Americanos y miembro del Museo Nacional de los Indios Americanos, que tiene sedes en Washington D.C. y la ciudad de Nueva York. Fue profesor en la Universidad de Arizona, donde inició el primer programa de Estudios sobre los indios americanos; también fue profesor en la Universidad de Colorado y en la Escuela de Leyes de Arizona. Su obra más famosa se titula Custer died for your sins. An indian manifesto ${ }^{36}$ en donde critica a la cultura occidental porque no vincula el conocimiento con la moral, sino que más bien conecta al poder con el conocimiento y los hace

${ }^{35}$ Llamado así cuando activistas indígenas estadounidenses tomaron la isla de Alcatraz, donde se localizaba la paradigmática cárcel, y la ocuparon durante 19 meses en 1969, convirtiéndola en un símbolo del Poder Rojo.

${ }^{36}$ Vine Deloria Jr., Custer died for your sins. An Indian Manifesto, http://www.feminish.com/wpcontent/uploads/2012/08/Custer_Died_for_Your_ Sins.pdf, consultado el 20 de marzo de 2004. 
equivalentes. El manifiesto sostiene que es necesario devolver la autonomía a las comunidades indígenas y denuncia el imperialismo cultural de la sociedad blanca occidental que se impone y desprecia a las otras culturas.

\section{La liga iroquesa y la democracia estadounidense}

\section{El bicentenario de la Constitución de los Estados Unidos de América}

En 1987, en el marco de las celebraciones de los doscientos años de la Constitución estadounidense, el Programa de Estudios sobre los Indios Norteamericanos de la Universidad de Cornell organizó el seminario Los Iroqueses, la Gran Ley de Paz y la Constitución de los Estados Unidos, en el que participaron unas doscientas personas, entre estudiantes y académicos. Ahí se discutió acerca de la posible y olvidada influencia de las naciones indias en la elaboración de la Carta Magna estadounidense. En este seminario se mostraron diversas evidencias según las cuales la Confederación Iroquesa aportó elementos sustantivos al sistema político norteamericano y a su Constitución.

Entre las ideas que se sostuvieron en este Congreso están las que planteó el doctor Grinde, del Gettysburg
College, resumen de lo que la mayoría de los participantes dijo:

La democracia moderna se estableció primero en América y no es el resultado de las teorías políticas europeas. La democracia estadounidense le debe su sello distintivo a los principios y la estructura de los gobiernos civiles de los indios. La Gran Ley de Paz instauró un gobierno de la gente, para la gente, por la gente. ${ }^{37}$

El mismo profesor sostuvo que Thomas Jefferson se inspiró en los símbolos de la leyenda del Peacemaker (pacificador) quien logró establecer el camino de la paz en medio de las sangrientas guerras tribales y, como símbolo de la Gran Ley de Paz, se dibujó un gran pino cuyas ramas se extienden para cobijar a todas las naciones que se comprometieran con ella; encima del pino se posa un águila.

${ }^{37}$ Donald A. Grinde Jr. y Bruce Elliot Johansen, Exemplar of Liberty: Native America and the Evolution of Democracy. A definitive study of how the founders of the United States combined European, American and Indian Ideas into a new political system, 1991, American Indian Studies Center, Angeles University. Estos autores sostienen que, entre los elementos de la organización iroquesa que influenciaron al sistema nortemericano están, por ejemplo, la idea de soberanía de cada estado y la unión confederada; la prohibición para los legisladores de participar en la guerra; y la separación entre los poderes civiles y militares, conceptos que no existían entonces en Europa. Tampoco tenían un mandato hereditario y sus naciones podían naturalizar y admitir a nuevos miembros. Existía el derecho de impugnación y las mujeres podían ser elegidas. 
Jefferson transformó el pino en el árbol de la libertad y el águila se sustituyó por las trece flechas que representan al nuevo gobierno estadounidense.

Algunas ideas parecidas fueron presentadas en otro libro del profesor Bruce Johansen, Forgotten Founders ${ }^{38}$ donde se muestran indicios de cómo Benjamín Franklin, Thomas Jefferson y otros de sus contemporáneos se inspiraron en las ideas políticas y sociales de los iroqueses y sus instituciones. También muestra cómo algunas de ellas se combinaron con la herencia cultural de los colonos europeos, lo que produjo una nueva realidad. Al principio del libro, Johansen transcribió la siguiente cita de Lewis $\mathrm{H}$. Morgan:

Las seis naciones mantienen prácticamente la misma relación con la liga iroquesa que los estados americanos tienen con la Unión [...] Todo su sistema político era contrario a la concentración de poder en las manos de cualquier persona individual, y proclive al principio de división de poderes entre numerosos iguales [...] La confederación iroquesa contiene los gérmenes del Congreso, del Parlamento y de la legislatura moderna. ${ }^{39}$

${ }^{38}$ Bruce E. Johasen, Forgotten founders. Benjamin Franklin, the Iroquois and the Rationale for the American Revolution, en http://www.ratical. org/many_worlds/6Nations/FF.pdf, consultada el 30 de marzo 2004.

${ }^{39}$ Ibid., cap. I, p. 3.
Algunos piensan que el reconocimiento de los aportes de las distintas minorías a la historia de Estados Unidos se enmarca dentro de las corrientes del multiculturalismo, apoyadas por la ONU desde 1982, cuando se iniciaron los trabajos que culminaron en la Declaración de los Derechos de los Pueblos Indigenas de 2007 y en las políticas multiculturales de la educación oficial norteamericana. Sin embargo, como se puede apreciar a lo largo de este breve artículo, el reconocimiento de los otros no es nuevo, tiene antecedentes en los escritos de la mayoría de los misioneros del siglo XVI; en las ideas que, desde finales del siglo XVII y durante el siglo XVIII, inspiraron a muchos ilustrados; y en los escritos de importantes antropólogos del siglo XIX. El racismo tampoco es nuevo, pero los grandes genocidios y fundamentalismos intolerantes del siglo XX tuvieron proporciones inauditas y mostraron que las posturas que acogían a los otros o fueron olvidadas o no tuvieron la fuerza y aceptación suficiente para contrarrestarlos. La mayoría de los antropólogos de la primera mitad del XX creían que desarrollo era sinónimo de occidentalización: había que transformar a los otros a la imagen y semejanza de los civilizados occidentales y, en este sentido, las posturas disidentes tuvieron poco eco; la unidad 
se entendía como homogeneidad cultural. Entonces, los otros levantaron sus voces para liberarse del dominio colonial o para exigir la igualdad ante la ley, como lo hicieron los movimientos de derechos civiles o para defender sus identidades y modos de ser, exigiendo el respeto a sus culturas ancestrales. Así, se pusieron otra vez en el centro del debate las relaciones interculturales, como en la época de la Ilustración. Se hizo patente que todos hemos recibido influencias unos de otros y que somos deudores, en muchos aspectos, de las culturas no occidentales. Todavía nos falta mucho para entender que todos estamos involucrados en el proceso de ir construyendo a la humanidad y en lo que significa el respeto a la dignidad de los otros y la de nosotros mismos, en la apasionante y compleja tarea de construir la unidad humana en medio de nuestra diversidad. 
CITAM Derechos Reservados.

La reproducción total o parcial de este artículo se podrá hacer si el ITAM otorga la autorización previamente por escrito. 